\title{
Departmental Structure, Cooperative Scholarship, and Productivity: A Fuzzy Set Qualitative-Comparative Analysis of Selected Sociology Departments
}

\author{
Ali Madanipour ${ }^{1, *}$, James Williams ${ }^{2}$ and Mahmoud Sadri ${ }^{2}$ \\ 1 Department of Sociology and Criminal Justice, Simpson College 701 N C St, Indianola, IA 50125, USA \\ 2 Department of Sociology and Social Work, Texas Woman's University, PO Box 425884, Denton, TX 76204, \\ USA; JWilliams2@twu.edu (J.W.); MSadri@twu.edu (M.S.) \\ * Correspondence: ali.madanipour@simpson.edu; Tel.: +86-515-961-1584
}

Academic Editor: Martin J. Bull

Received: 19 February 2017; Accepted: 26 May 2017; Published: 2 June 2017

\begin{abstract}
Previous studies of scholarly productivity have neglected the impact of departmental and institutional structure on the outcome. This study examines the relationships between departmental and institutional structure, cooperative scholarship, and individualistic scholarship with productivity in 31 highly ranked sociology departments in the United States. We measure scholarly productivity by the number of peer reviewed articles that were published either jointly or individually by faculty members during 2009-2010. By applying fuzzy set qualitative comparative analysis, we conclude that a combination of four conditions are associated with higher levels of scholarly productivity. These are: type of institution (public vs. private), proportion of tenured professors, individualistic scholarship, and cooperative scholarship. The results reveal that the conditions (independent variables) combine in different ways (pathways) to be sufficient for the outcome. Further, we conclude that cooperative scholarship and productivity are more complex constructs than suggested by previous literature and that there are multiple pathways by which departments may facilitate scholarly productivity. We address implications and recommendations for future research.
\end{abstract}

Keywords: scholarly productivity; cooperative scholarship; individualistic scholarship; qualitative comparative analysis; sociology; United States

\section{Introduction}

Three decades before Thomas Kuhn conceived of scientific activity as a communal (both cooperative and competitive) phenomenon, Ludwig Fleck wrote a superb monograph in German entitled: "Genesis and Development of Scientific Fact" in which he proposed: "The thought style is a social product: it is formed within a collective of social forces. This circumstance links problems of natural science with those of sociology and especially the sociology of thought, a science which unfortunately still remains grossly neglected, but is bound soon to move into the center of intellectual interest" (Fleck 1979; Fleck 1935). The sociology of science, pioneered in 1970s by Robert K. Merton and Harriet Zuckerman, laid bare the social scientific foundations of the scientific activity. They underlined the significance of cooperation both among colleagues and between mentors and students as an essential component of scientific research and activity (Merton 1973; Zuckerman 1977). Harold Garfinkel illuminated the role of conversation, negotiation, and consensus building among colleagues in the emergence of scientific studies (Garfinkel 1957). It remained for the "Reflexive Sociology" of Bourdieu to apply the insights of Sociology of Science to sociology itself (Bourdieu 1984; Bourdieu and Wacquant 1992). 
Science is a social as well as cultural institution where advances depend on interactions among scientists (Kuhn 1970; Garfinkel 1957; Merton 1973). However, the patterns of interactions between scientists differ across various disciplinary fields. With regards to scholarship activities, as Lewis, Ross, and Holden demonstrate, natural science faculties rarely conduct research alone. The faculties in humanities mainly work alone and social scientists conduct an approximately even mixture of sole and joint authorship (O'Brien 2012). The evolution of cooperative scholarship parallels the development of modern universities with their increasingly complex array of interconnected faculties, colleges, schools, and departments (Lewis et al. 2012; Leahey and Reikowsky 2008).

Scientific cooperation is a multi-dimensional and multi-level concept. Scientific and research cooperation is defined as researchers working together to achieve the common goal of producing new scientific knowledge (Katz and Martin 1997). To measure scientific cooperation, there are various ways such as conducting surveys or collecting data from individuals' CVs and relying on coauthorship patterns (Leahey 2016). In the literature, international scientific cooperation is deemed a positive development (Logsdon 1984; Hagen 1987; Uller 1993; Barblan 2002; Grothus 2003; Papon 2004; Peretroukhine et al. 2004; Beerkens and Derwende 2007; Arunachalam and Viswanathan 2008; Teune 1966; Radda 2002; Peterson 2001). A substantial number of studies have focused on intra-disciplinary and interdisciplinary cooperation among scholars (Lewis et al. 2012; Abramo et al. 2009; Fox and Faver 1984; Van Rijnsoever and Hessels 2011). In his study of cooperation among sociologists from 1963 to 1999, Moody argues that participation in the sociology collaboration network depends on research specialty and that quantitative work is more likely to be co-authored than non-quantitative work. However, structural embeddedness within the network core given collaboration is largely unrelated to specialty area (Moody 2004). Conversely, Leahey and Reikowsky - by studying academic cooperation among sociologists-conclude that most of the papers in their sample were written by scholars who joined with like-minded others to produce a paper on a familiar topic. This style of collaboration extends the sole-author tradition in a way that may improve efficiency and productivity, but rarely pushes subfield boundaries in new ways (Lewis et al. 2012).

Wolfe, by distinguishing between two scholarly cultures within sociology departments, argues that while some sociology departments are book oriented, sociologists in some departments prefer to publish articles. He demonstrates that not only do specific university departments have scholarly cultures emphasizing one or the other, but that structural and demographic factors-such as location, public or private status, and size-are correlated with each orientation. According to him, book departments tend to be found at exclusive private universities in or near big cities on both coasts, while article-producing departments tend to be in land grant universities in the South and Midwest (Wolfe 1990).

According to O'Brien, compared to those who received their PhDs between 1953 and 1962, scientists who entered the workforce between 1983 and 1991 coauthored approximately one-third more of their early career articles (Leahey and Reikowsky 2008). This increase in cooperative works has given rise to discussions on the connections between cooperation and productivity. Although many studies suggest that cooperation among scientists influences efficiency and productivity (Abramo et al. 2009; Katz and Martin 1997; Presser 1980; Lee and Bozeman 2005; Leahey 2016; Rawlings and McFarland 2011), others argue that productive scientists are independent, self-sufficient, and self-directed (Fox and Faver 1984).

There remains an important aspect of the cooperation debate that has been, hitherto, neglected. How do cooperative and individualistic scholarship affect a department's scholarly productivity? Are productive departments more cooperative in terms of their scholarship activities? What are the similarities and differences between these departments with regards to productivity, individualistic research, and cooperative scholarship?

Using fuzzy sets qualitative comparative analysis (QCA), we address these questions and limitations. The specific purpose of this study to examine the relationships between departmental/institutional 
structure and individualistic/cooperative scholarship with scholarly productivity in a sample of 31 highly rated sociology departments. The previous literature mostly emphasizes the net effects of independent variables on the outcomes. However, applying QCA allows us to not only discuss the similarities and differences between selected departments in terms of productivity and scholarship, but also to discuss causal complexity by demonstrating the different patterns of relations between structural conditions and scholarly outcomes in various departments. We demonstrate that different conditions combine in various ways to become sufficient for productivity as outcome.

\section{Theoretical Framework}

It seems various theories of group processes are useful in understanding the nature of cooperative scholarship and productivity. For instance, according to exchange network theorists, cooperation can be seen as a direct productive exchange between actors (Yamagishi and Cook 1993). In productive exchange, two or more actors can produce a joint outcome by contributing their individual resources or talents to the collective endeavor that benefits both (or all) of them (Lawler and Yoon 1996; Molm 2006). Thus, from the viewpoint of exchange network theory, this kind of exchange reflects the exact definition of cooperation. Lawler, Thye, and Yoon argue that productive exchange is indirect and generalized in the sense that it entails a person-to-group and group-to-person exchange. According to them, productive exchange is a group oriented, coordination task in which actors seek to produce a valued result through their joint collaboration (Lawler et al. 2000).

There are persuasive arguments, especially among exchange network theorists, that frequent social exchanges can influence cooperation by increasing trust and social capital in exchange relations (Cook 2005; Bloch et al. 2007). They also engender or encourage a sense of control, positive emotions, cohesion (Lawler et al. 2006), reciprocity (Molm et al. 2007), and group identity (Kollock 1998). In their theory of relational cohesion, Lawler and Yoon posit that structural power indirectly produces commitment through a sequence of theoretically-specified steps. What they call the "endogenous process" encompasses behavior (exchange frequency), mild positive emotions (pleasure/satisfaction, interest/excitement), and perceptions of the relation as a unit (relational cohesion) (Lawler and Yoon 1996).

In addition, there is some evidence that larger networks engender more cooperation than smaller ones. It appears that in large networks, actors can find more alternatives to begin or continue exchange relations (Molm 2006). Moreover, some studies pay attention to cooperative behaviors in large networks as an intervening variable for other outcomes. According to Milton and Westphal, membership in a large, structurally equivalent subgroup will increase individual performance through higher average cooperation with other group members (Milton and Westphal 2005). On the other hand, some other studies emphasize the negative effect of network size on cooperation. Borrowing from Putnam; Hunt, Karlan, Möbius, Rosenblat, and Szeidl argue that a large community is often negatively correlated with pro-social behaviors such as formal volunteering, working on public projects, and giving informal help to friends and strangers. This may be because people who reside in large communities simply spend less time socializing with each other. As a result, people living in large communities have, on average, fewer friends and their social networks support less cooperation (Hunt et al. 2007).

Some studies also emphasize situations in which power-disadvantaged actors continue their cooperative behaviors with actors who hold more powerful positions. Many experimental investigations have found that most subjects will continue to cooperate or exchange under reward inequity as long as it is more rewarding for both persons than an alternative response (Molm 1981). This power imbalance within the departments as we will discuss in the next section is measured by percentage of tenured faculty in the department. We want to know that how and in which combinations the dominance of tenured faculty affects high or low scholarly productivity.

Through an examination of previous research, we have identified several structural factors that are expected to affect scholarly productivity. These are cooperative or individualistic scholarship within the departments, the type of the department (public or private), and the dominance of tenured professors. 
We pose two questions: In what ways do these factors combine to be sufficient for producing scholarly productivity in the selected departments? What are the similarities and differences between the selected sociology departments in terms of productivity as well as cooperative or individualistic scholarship?

\section{Methods}

\subsection{Fuzzy Set Analysis}

Through an examination of previous research we have identified several structural factors that are expected to affect productivity as well as cooperative or individualistic scholarship within the departments. These are the type of the department (public or private), size of the department, occurrence of frequent forums in the department, and the dominance of tenured professors. We pose two questions: In what ways do these factors combine to be sufficient for producing cooperative or individualistic scholarship in the selected departments? What are the similarities and differences between the selected sociology departments in terms of productivity as well as cooperative or individualistic scholarship?

Based on the nature of the research questions, we have applied Fuzzy Set Qualitative Comparative Analysis (FsQCA) in this study (Ragin 1987). Conventional quantitative methods insist on recognizing the general patterns of variables as well as the net effect of each independent variable on each dependent variable. In FsQCA logic, the key issue is not which variable is the strongest (i.e., has the biggest net effect) but how different conditions combine and whether there is only one combination or several different combinations of conditions (referred to as 'causal recipes') capable of generating the same outcome (Ragin 2008). Therefore, the analysis of causal complexity is central to this approach (Ragin 2000; Rihoux and Ragin 2009). Causal complexity is defined as a situation in which a given outcome may follow from several different combinations of causal conditions-from different 'causal recipes' (Ragin 2008). As mentioned before, the aim of the current study is not only to understand the conditions associated with academic cooperation within the selected departments, but also to examine these departments in terms of their broad similarities and differences based on different combinations of conditions for cooperative scholarship and productivity.

\subsection{Research Cases}

The optimal research cases in qualitative comparative research are between 10 and 50 (Ragin 2000). On the other hand, to be able to study causal complexity, it is important to simultaneously make a balance between heterogeneity and homogeneity of research cases (Ragin 2000). We had planned to collect data for 50 highly ranked sociology departments. However, it was difficult and very time consuming to collect data for all the faculty members within the 50 departments. In the current study, based on the National Research Council rankings, we have included only the first 31 cases selected from among the highly ranked sociology departments in the United States (NRCRSP 2010). The only exception is University of California-San Francisco that we could not find enough data for its faculty. So we decided to eliminate it from the analyses. Therefore, our cases are as follows: University of Arizona, UC Berkeley, Brown, Chicago, Columbia, Cornell, Duke, Harvard, Indiana, Iowa, Johns Hopkins, Miami, Michigan, Northwestern, Notre Dame, NYU, Ohio State, Pennsylvania State, U of Pennsylvania, Princeton, Rutgers, Stanford, SUNY-Albany, Temple, Texas-Austin, U of Washington, UCLA, UC-Santa Barbara, UNC, Wisconsin Madison, and Yale University.

\subsection{Data}

We have gathered data from two main sources: university and departmental websites and professors' curriculum vitae, which were downloaded from departmental web sites. The data for the professors' scholarship and rankings are directly gathered from their curriculum vitae. For some departments, it was difficult to access professors' most updated curriculum vitae in their websites, so we contacted them directly to obtain their updated vitae. In addition, we used the information on 
the university and department websites to collect data on the type of university within which each department resides. Table 1 shows the measurement procedures for each variable. In the current research, we have used professors' peer reviewed articles to measure 'productivity' and 'scholarship cooperation'. We have demonstrated the descriptive statistics for the original data in Table 2.

Table 1. Variables and Measurement.

\begin{tabular}{cc}
\hline Variables (Sets) & Measurement \\
\hline Productivity & Mean number of articles published by each faculty member during 2009-2010 \\
Cooperative Scholarship & Percentage of joint articles published by each faculty member during 2009-2010 \\
Individualistic Scholarship & Percentage of individually published articles by each faculty during 2009-2010 \\
Tenured Dominant & Percentage of department faculty who are Full/ Associate Professors \\
Department's Type (Public) & Public or Private \\
\hline
\end{tabular}

Table 2. Descriptive Statistics.

\begin{tabular}{cccccc}
\hline Set & Mean & Std. Dev. & Minimum & Maximum & N Cases \\
\hline Productivity & 2.75 & 0.86 & 1 & 5 & 31 \\
Cooperative Scholarship & 1.92 & 0.91 & 0.5 & 4.5 & 31 \\
Individualistic Scholarship & 0.84 & 0.41 & 0.41 & 1.83 & 31 \\
Tenured Dominant & 0.83 & 0.07 & 0.65 & 1.00 & 31 \\
Department's Type (Public) & 0.52 & 0.50 & 0 & 1 & 31 \\
\hline
\end{tabular}

\subsection{Variables}

In terms of the conditions (independent variables), we have used the following variables: the type of department (public =1), dominance of tenured faculties (the percentage of faculty who are associate and full professors), cooperative scholarship (the mean number of joint articles published by faculties during 2009-2010), and individualistic scholarship (the mean number of peer-reviewed articles that are published individually per faculty member). As Table 1 indicates, since the final units of analysis in this study are academic departments, we have computed new variables for the departmental level based on data from individual faculty. By calibrating data and creating new fuzzy membership scores based on the original data, we have defined the new sets which are used in the analysis. As mentioned before, by applying FsQCA we aim to identify how these conditions combine in various ways to be sufficient for productivity and cooperative scholarships.

\subsection{Calibration}

The key step in Qualitative Comparative Analysis is well-constructed fuzzy sets, which in turn raises the issue of calibration which means that scores must be interpreted according to external standards that have face validity (Ragin 2008). As shown in Table A1 of Appendix A, external standards can be implemented by specifying the values of an interval scale that correspond to the three qualitative breakpoints that structure a fuzzy set: full membership, full non-membership, and the crossover point. These three benchmarks are then used to transform the original interval-scale values to fuzzy membership scores.

The end product, as shown in Table A2, is the fine grained calibration of the degree of membership of cases in different sets, with fuzzy scores ranging from 0.0 to 1.0 (Ragin 2008). Thus, the calibration of membership in a fuzzy set involves both quantitative and qualitative assessment (Ragin 2000).

\section{Findings}

\section{Scholarship Productivity}

With fuzzy sets, set A is a subset of set B if the membership scores of cases in set A are less than or equal to their respective membership scores in set B (Ragin 2000). Whenever a causal condition is 
necessary but not sufficient for an outcome, instances of the outcome will form a subset of instances of the causal condition (Ragin 2000). In the analysis of necessary conditions, we assess whether the observed proportion is significantly greater than the benchmark of 0.80 which we have assigned. In a case where the observed proportion is significantly greater than the benchmark proportion, we can interpret this finding as support for the argument that the causal condition is usually necessary for the outcome (Ragin 2000). As shown in Appendix B, the results of the analyses of necessary conditions for 'productivity' reveal that because of the consistency scores greater than the benchmark of 0.80 , cooperative scholarship is the only necessary condition for productivity.

The study of sufficiency as Ragin argues is central to the study of causal complexity (Ragin 2000). "A cause is defined as sufficient if by itself it can produce a certain outcome while a cause is defined as necessary if it must be present for a certain outcome to occur" (Ragin 1987). According to Ragin, the finding that a cause or causal combination is a subset of an outcome supports the argument of sufficiency (Ragin 2000).

As shown in Table 3, we found two important pathways for high levels of productivity. According to the first pathway, some sociology departments-both public and private-are productive because of the salience of cooperative (not individualistic) scholarships. This combination is sufficient for high productivity at Miami, Pennsylvania State, University of Washington, Harvard, Duke, Iowa, Brown, Texas-Austin, University of North Carolina, Ohio State, Yale, Cornell, Princeton, and Michigan. The cases that support each recipe are demonstrated in the table. The relative number of cases in a path is a direct indicator of the empirical importance of a causal combination (Ragin 2003a). A membership score greater than 0.5 in a causal combination signals that a case is more in than out of the causal combination in question. A score greater than 0.5 also indicates which corner of the multidimensional vector space formed by causal conditions a given case is closest to (Rihoux and Ragin 2009).

In the second pathway, the configuration of four causal conditions is sufficient for productivity. In this pathway, being a private university combines with the dominance of tenured faculty, individualistic (not cooperative) scholarship to be sufficient for productivity. This pathway is supported by University of Pennsylvania and Northwestern University.

Table 3. Analysis of Sufficiency for Scholarly Productivity

\begin{tabular}{|c|c|c|c|c|}
\hline \multicolumn{5}{|c|}{$\begin{array}{c}\text { Model: Productivity }=\mathrm{f}(\text { public, tenured dominant, cooperative, individualistic) } \\
\text { Frequency Cutoff: } 2.0 \text {; Consistency Cutoff: } 0.85\end{array}$} \\
\hline & $\begin{array}{c}\text { Raw } \\
\text { Coverage }\end{array}$ & $\begin{array}{l}\text { Unique } \\
\text { Coverage }\end{array}$ & Consistency & \\
\hline $\begin{array}{l}\text { individualistic* } \\
\text { COOPERATIVE }\end{array}$ & 0.83 & 0.63 & 0.84 & $\begin{array}{c}\text { Miami }(0.95,0.95), \text { Pennsylvania State } \\
(0.9,0.84), \text { U of Washington }(0.89,0.62), \\
\text { Harvard }(0.84,0.84), \text { Duke }(0.82,0.81), \\
\text { Iowa }(0.82,0.43), \text { Brown }(0.79,0.59), \\
\text { Texas-Austin }(0.79,0.81), \\
\text { UNC }(0.71,0.65), \text { Ohio State }(0.71,0.59), \\
\text { Yale }(0.68,0.53), \text { Cornell }(0.68,0.67), \\
\text { Princeton }(0.61,0.81), \\
\text { Michigan }(0.57,0.59)\end{array}$ \\
\hline $\begin{array}{l}\text { INDIVIDUALISTIC * } \\
\text { cooperative * } \\
\text { TENURED DOMINANT * } \\
\text { public }\end{array}$ & 0.22 & 0.02 & 0.81 & $\begin{array}{l}\text { Pennsylvania }(0.55,0.91) \text {, } \\
\text { Northwestern }(0.53,0.56)\end{array}$ \\
\hline \multicolumn{5}{|c|}{ solution coverage: 0.85 ; solution consistency: 0.83} \\
\hline
\end{tabular}

Note: * We have shown the original defined sets with upper cases and the negation of the set with the lower cases.

The key finding here is that there is not just one condition that is solely sufficient for productivity. Table 3 indicates that causal conditions combine in different ways to be sufficient for productivity. In the case of our analysis, for instance there are some public and some private universities with high 
fuzzy scores in productivity. However, being public or private needs to combine with other conditions to be sufficient for productivity.

Finally, we address which departments have published the most peer reviewed articles and which departments were more collaborative as opposed to focusing on individual scholarship. This allows us to consider the relationships between individual and cooperative scholarship and peer-reviewed article production.

As shown in Table 4, from among 31 cases, we identified 18 departments (from public and private institutions) with high scores in peer reviewed article production. However, as mentioned before, the patterns of article production differ. Some departments have received high scores in cooperative scholarship and some others have received high fuzzy scores in individualistic scholarship. Pennsylvania State, Texas-Austin, University of California-Los Angeles, University of North Carolina, University of Washington, Michigan, and Ohio State are examples of public universities that are highly productive and have more cooperative scholarship. From among private universities, Harvard, Miami, Duke, Princeton, Cornell, Brown, and Yale received high scores in productivity and in cooperative scholarship.

On the other hand, as Table 4 indicates, there are some departments in which faculty members have produced mostly individual works. Berkeley and Rutgers are two examples of highly productive public departments with more individualistic preferences. Among private universities, Northwestern University and the University of Pennsylvania are two examples of highly productive departments in which their faculty members produced their articles mostly individually. Hence, Table 4 suggests that high productivity can be attained through a focus on cooperative scholarship, or a focus on individual scholarship.

Table 4. Productive Departments based on the type of Institutions and type of Scholarship Activities.

\begin{tabular}{lcc}
\hline & \multicolumn{2}{c}{ High Productive } \\
\cline { 2 - 3 } & Public & Private \\
\hline & Pennsylvania State & Harvard \\
& Texas-Austin & Miami \\
Cooperative Scholarship & UCLA & Duke \\
& UNC & Princeton \\
& U of Washington & Cornell \\
& Michigan & Brown \\
& Ohio State & Yale \\
\hline \multirow{2}{*}{ Individualistic Scholarship } & Rutgers & Pennsylvania \\
& Berkeley & Northwestern \\
\hline
\end{tabular}

\section{Discussion and Conclusions}

Using fuzzy set qualitative comparative analysis, this study explored scholarship productivity in 31 highly ranked sociology departments in the United States during 2009 and 2010. We do not aim to generalize the results to other departments, or to a wider period of time. Additionally, the results are limited only to the production of peer-reviewed articles (not books or book chapters) within a two year period in the above-mentioned departments.

By applying the fuzzy set approach, we examined the general question of which configurations of departmental and university characteristics are sufficient for peer-reviewed article production in the selected departments. With regard to scholarly productivity, the results presented in Appendix B demonstrate that the consistency score for cooperative scholarship is higher than the benchmark of 0.80 , so it can be considered as a necessary condition for productivity. This is consistent with previous research on scholarly productivity, which has also shown that colleagues who publish jointly will probably be more productive than others (Abramo et al. 2009; Katz and Martin 1997; Presser 1980; Lee and Bozeman 2005). As we noted above, cooperative scholarship is not the only 
route to productivity. Indeed, high productivity may be attained at schools that mainly emphasize individualistic scholarship, or emphasize collaboration.

We demonstrated that conditions combine in different ways to be sufficient for scholarly productivity. This differs from the results of previous studies in that we find that cooperative scholarship is a more complex phenomenon than argued in previous studies and that there are different approaches by which it can be attained. For instance, some studies argue that cooperative scholarship is more common in public rather than private institutions (O'Brien 2012). This might be related to the different patterns of grant policies in public and private universities which force professors in public universities to see cooperation as an efficient grant seeking strategy (O'Brien 2012). Also, our findings differ from Wolfe who argued for the existence of distinct scholarly cultures among public and private universities (Wolfe 1990). Our results demonstrated that cooperative scholarship and article production are not limited to certain institutions such as public universities. Instead, various conditions combine in different ways to be sufficient for peer-reviewed article production. Further, we find also that scholarly productivity is a complex phenomenon that is best approached in a fashion that recognizes the possibility that there are different routes by which departments can become productive.

With regard to the relationships between productivity and individualistic or cooperative scholarship, our results not only supported the arguments of some scholars who emphasized the positive relationship between cooperation and productivity (Abramo et al. 2009; Katz and Martin 1997; Presser 1980; Lee and Bozeman 2005), but also some who believed that productive scientists are independent, self-sufficient, and self-directed (Fox and Faver 1984). Therefore, productivity is not exclusively related to either cooperative or individual works but to both. This is a finding that is at variance with previous research, and as was the case with cooperative scholarship, indicates that factors associated with productivity are more complex than are normally assumed in a traditional, linear approach to identifying determinants of productivity.

The findings suggest also that a qualitative comparative approach as used in this study can contribute significant insights to understanding the nature of scholarly productivity and can shed light on the conditions that are most associated with the outcome. For example, our application of this approach has demonstrated that highly ranked sociology departments in our sample have taken distinct routes to attaining high levels of scholarly productivity. Specifically, we identified two important pathways that lead to high levels of scholarly productivity. In addition, we have demonstrated that the role of cooperative scholarship in facilitating productivity is not a simple linear relationship, as previous studies have assumed. Rather, we have demonstrated that departments can attain high levels of productivity by focusing on collaborative scholarship but that it is also possible for departments to be highly productive and maintain an emphasis on individualistic scholarship.

There are a number of directions in which the results of this study can be extended. Future research can profitably reexamine the measurement of productivity and scholarship cooperation by incorporating other measures of productivity such as the number of published books and book chapters. These data are also available from faculty CVs on the internet. Expanding the study to additional years is warranted as well. In addition, including new conditions for the analyses of sufficiency will be enlightening. Additional research may also examine productivity and scholarship activities within a larger sample of departments. Qualitative comparative analysis has the potential to offer additional substantive insights into cooperative scholarship, scholarly productivity, and other topics in the sociology of knowledge as well.

Acknowledgments: We would like to thank the anonymous reviewers for their positive and very helpful comments on the manuscript.

Author Contributions: Ali Madanipour conceived the problem and analyses, collected and analyzed the data, and performed the analyses. Ali Madanipour, James Williams and Mahmoud Sadri wrote the paper collaboratively.

Conflicts of Interest: The authors declare no conflict of interest. 


\section{Appendix A}

Table A1. Fuzzy Thresholds for Calibration.

\begin{tabular}{cccc}
\hline Variables (Sets) & Full Membership & Crossover & Full Non-Membership \\
\hline Productivity & 5.0 & 2.5 & 0.5 \\
Cooperative Scholarship & 0.90 & 0.70 & 0.25 \\
Individualistic Scholarship & 0.75 & 0.30 & 0.10 \\
Tenured Dominant & 0.76 & 0.85 & 0.65 \\
Department's Type (Public) & 1 & - & 0 \\
\hline
\end{tabular}

Table A2. Fuzzy Membership Score of Research Cases in the Sets.

\begin{tabular}{|c|c|c|c|c|c|}
\hline University & Public & $\begin{array}{c}\text { Tenured } \\
\text { Dominant }\end{array}$ & $\begin{array}{l}\text { Individualistic } \\
\text { Scholarship }\end{array}$ & $\begin{array}{l}\text { Cooperative } \\
\text { Scholarship }\end{array}$ & $\begin{array}{c}\text { Scholarly } \\
\text { Productivity }\end{array}$ \\
\hline Arizona & 1 & 0.46 & 0.7 & 0.3 & 0.43 \\
\hline Berkeley & 1 & 0.73 & 0.95 & 0.05 & 0.50 \\
\hline Brown & 0 & 0.77 & 0.21 & 0.79 & 0.59 \\
\hline Chicago & 0 & 0.26 & 0.69 & 0.31 & 0.46 \\
\hline Columbia & 0 & 0.18 & 0.84 & 0.16 & 0.39 \\
\hline Cornell & 0 & 0.39 & 0.32 & 0.68 & 0.67 \\
\hline Duke & 0 & 0.77 & 0.18 & 0.82 & 0.81 \\
\hline Harvard & 0 & 0.73 & 0.16 & 0.84 & 0.84 \\
\hline Indiana & 1 & 0.5 & 0.26 & 0.74 & 0.26 \\
\hline Iowa & 1 & 0.55 & 0.18 & 0.82 & 0.43 \\
\hline Johns Hopkins & 0 & 0.55 & 0.46 & 0.54 & 0.21 \\
\hline Miami & 0 & 0.43 & 0.05 & 0.95 & 0.95 \\
\hline Michigan & 1 & 0.46 & 0.43 & 0.57 & 0.59 \\
\hline Northwestern & 0 & 0.83 & 0.53 & 0.47 & 0.56 \\
\hline Notre Dame & 0 & 0.07 & 0.78 & 0.22 & 0.23 \\
\hline NYU & 0 & 0.55 & 0.82 & 0.18 & 0.32 \\
\hline Ohio State & 1 & 0.32 & 0.29 & 0.71 & 0.59 \\
\hline Penn State & 1 & 0.5 & 0.1 & 0.9 & 0.84 \\
\hline Pennsylvania & 0 & 0.6 & 0.55 & 0.45 & 0.91 \\
\hline Princeton & 0 & 0.46 & 0.39 & 0.61 & 0.81 \\
\hline Rutgers & 1 & 0.26 & 0.72 & 0.28 & 0.65 \\
\hline Stanford & 0 & 0.18 & 0.68 & 0.32 & 0.46 \\
\hline SUNY-Albany & 1 & 0.26 & 0.39 & 0.61 & 0.32 \\
\hline Temple & 1 & 0.32 & 0.82 & 0.18 & 0.10 \\
\hline Texas-Austin & 1 & 0.77 & 0.21 & 0.79 & 0.81 \\
\hline $\mathrm{U}$ of Washington & 1 & 0.43 & 0.11 & 0.89 & 0.62 \\
\hline UCLA & 1 & 0.69 & 0.5 & 0.5 & 0.65 \\
\hline UC-Santa Barbara & 1 & 0.95 & 0.91 & 0.09 & 0.43 \\
\hline UNC & 1 & 0.16 & 0.29 & 0.71 & 0.65 \\
\hline Wisconsin Madison & 1 & 0.12 & 0.57 & 0.43 & 0.26 \\
\hline Yale & 0 & 0.05 & 0.32 & 0.68 & 0.53 \\
\hline
\end{tabular}




\section{Appendix B}

Table A3. Analysis of Necessary Conditions for Scholarly Productivity.

\begin{tabular}{ccc}
\hline & \multicolumn{2}{c}{ Outcome: Productivity } \\
\cline { 2 - 3 } & Consistency & Coverage \\
\hline COOPERATIVE SCHOLARSHIP & 0.83 & 0.84 \\
cooperative scholarship & 0.58 & 0.68 \\
INDIVIDUALISTIC SCHOLARSHIP & 0.58 & 0.68 \\
individualistic Scholarship & 0.83 & 0.84 \\
PUBLIC & 0.48 & 0.51 \\
public & 0.52 & 0.58 \\
TENURED DOMINANT & 0.70 & 0.83 \\
tenured dominant & 0.70 & 0.71 \\
\hline
\end{tabular}

Notes: * We have shown the original defined sets with upper cases and the negation of the set with the lower cases. For instance, consistency and coverage scores of the set of 'public' shows the subset superset relations of not PUBLIC departments with the set of outcome.

\section{References}

Abramo, Giovanni, Ciriaco A. D’Angelo, and Flavia D. Costa. 2009. Research Collaboration and Productivity: Is there Correlation? Higher Education 57: 155-71.

Arunachalam, Subbiah, and B. Viswanathan. 2008. South-South Cooperation: The Case of Indo-Chinese Collaboration in Scientific Research. Current Science 95: 311-13.

Barblan, Andris. 2002. Academic Cooperation and Mobility in Europe: How it was and how it will be. Higher Education in Europe 27: 31-58. [CrossRef]

Beerkens, Eric, and Marijk Derwende. 2007. The Paradox in International Cooperation: Institutionally Embedded Universities in a Global Environment. Higher Education 53: 61-79. [CrossRef]

Bloch, Francis, Garance Genicot, and Debraj Ray. 2007. Reciprocity in Groups and the Limits to Social Capital. The American Economic Review 97: 65-69. [CrossRef]

Bourdieu, Pierre. 1984. Homo Academicus. Palo Alto: Stanford University Press.

Bourdieu, Pierre, and Loic Wacquant. 1992. Invitation to Reflexive Sociology. Chicago: University of Chicago Press. Cook, Karen S. 2005. Networks, Norms, and Trust: The Social Psychology of Social Capital 2004 Cooley Mead Award Address. Social Psychology Quarterly 68: 4-14. [CrossRef]

Fleck, Ludwik. 1935. Entstehung und Entwicklung Einer Wissenschaftlichen Tatsache: Einfuehrung in die Lehre vom Denkstil und Denkkollektiv. Basel: Benno Schabe Co.

Fleck, Ludwik. 1979. The Genesis of Scientific Fact. Chicago: The University of Chicago Press.

Fox, Mary F., and Catherine A. Faver. 1984. Independence and Cooperation in Research: The Motivations and Costs of Collaboration. The Journal of Higher Education 55: 347-59. [CrossRef]

Garfinkel, Harold. 1957. Studies in Ethnomethodology. Malden: Blackwell Publishers Inc.

Grothus, Ulrich. 2003. The Contribution of International Academic Cooperation and Exchange to the Development and Advancement of Society. Higher Education in Europe 28: 109-11. [CrossRef]

Hagen, Jon. 1987. University Co-Operation and Academic Recognition in Europe: The Council of Europe and the Communities. European Journal of Education 22: 77. [CrossRef]

Hunt, Allcott, Dean Karlan, Markus M. Möbius, Tanya S. Rosenblat, and Adam Szeidl. 2007. Community Size and Network Closure. The American Economic Review 97: 80-85.

Katz, J. Sylvan, and Ben R. Martin. 1997. What is Research Collaboration? Research Policy 26: 1-18. [CrossRef]

Kollock, Peter. 1998. Social Dilemmas: The Anatomy of Cooperation. Annual Review of Sociology 24: 183-214. [CrossRef]

Kuhn, Thomas S. 1970. The Structure of Scientific Revolutions. Chicago: University of Chicago Press.

Lawler, Edward J., and Jeongkoo Yoon. 1996. Commitment in Exchange Relations: Test of a Theory of Relational Cohesion. American Sociological Review 61: 89-108. [CrossRef]

Lawler, Edward J., Shane R. Thye, and Jeongkoo Yoon. 2000. Emotion and Group Cohesion in Productive Exchange. American Journal of Sociology 106: 616-57. [CrossRef] 
Lawler, Edward J., Shane R. Thye, and Jeongkoo Yoon. 2006. Commitment in Structurally Enabled and Induced Exchange Relations. Social Psychology Quarterly 69: 183-200.

Leahey, Erin. 2016. From Sole Investigator to Team Scientist: Trends in the Practice and Study of Research Collaboration. Annual Review of Sociology 42: 81-100. [CrossRef]

Leahey, Erin, and Ryan C. Reikowsky. 2008. Research Specialization and Collaboration Patterns in Sociology. Social Studies of Science 38: 425-40. [CrossRef]

Lee, Sooho, and Barry Bozeman. 2005. The Impact of Research Collaboration on Scientific Productivity. Social Studies of Science 35: 673-702. [CrossRef]

Lewis, Jenny, Sandy Ross, and Thomas Holden. 2012. The How and Why of Academic Collaboration: Disciplinary Differences and Policy Implications. Higher Education 64: 693-708. [CrossRef]

Logsdon, John M. 1984. U.S.-European Cooperation in Space Science: A 25-Year Perspective. Science 223: 11-16. [CrossRef] [PubMed]

Merton, Robert K. 1973. The Sociology of Science: Theoretical and Empirical Investigations. Chicago: University of Chicago Press.

Milton, Laurie P., and James D. Westphal. 2005. Identity Confirmation Networks and Cooperation in Work Groups. The Academy of Management Journal 48: 191-212. [CrossRef]

Molm, Linda D. 1981. The Conversion of Power Imbalance to Power Use. Social Psychology Quarterly 44: 151-63. [CrossRef]

Molm, Linda D. 2006. The Social Exchange Framework. In Contemporary Social Psychology Theories. Edited by Peter J. Burke. Palo Alto: Stanford University Press.

Molm, Linda D., David R. Schaefer, and Jessica L. Collett. 2007. The Value of Reciprocity. Social Psychology Quarterly 70: 199-217. [CrossRef]

Moody, James. 2004. The Structure of Social Science Collaboration Network: Disciplinary Cohesion from 1963 to 1999. American Sociological Review 69: 213-38. [CrossRef]

The National Research Council Rankings of Sociology Programs. Available online: http:/ / chronicle.com/article/ nrc-sociology /124663 (accessed on 29 September 2010).

O’Brien, Timothy L. 2012. Change in Academic Co-Authorship, 1953-2003. Science, Technology, and Human Values 37: 210-34. [CrossRef]

Papon, Pierre. 2004. European Scientific Cooperation and Research Infrastructures: Past Tendencies and Future Prospects. Minerva: A Review of Science, Learning E Policy 42: 61-76.

Peretroukhine, V.F., F. David, and C. Madic. 2004. Development of the French-Russian Scientific Cooperation in Radiochemistry. Radiochemistry 46: 315-23. [CrossRef]

Peterson, Mark F. 2001. International Collaboration in Organizational Behavior Research. Journal of Organizational Behavior 22: 59-81. [CrossRef]

Presser, Stanley. 1980. Collaboration and the Quality of Research. Social Studies of Science 10: 95-101. [CrossRef]

Radda, George. 2002. Biomedical Research and International Collaboration. Science 295: 445-46. [CrossRef] [PubMed]

Ragin, Charles C. 1987. The Comparative Method. Berkeley: University of California Press.

Ragin, Charles C. 2000. Fuzzy-Set Social Science. Chicago: University of Chicago Press.

Ragin, Charles C. 2003a. Recent Advances in Fuzzy-Set Methods and Their Application to Policy Questions. COMPASSS Working Paper WP2003-9. Available online: http:/ /www.compasss.org/wpseries/Ragin2003a.pdf (accessed on 31 August 2003).

Ragin, Charles C. 2008. Redesigning Social Inquiry: Fuzzy Sets and Beyond. Chicago: University of Chicago Press.

Rawlings, Craig M., and Daniel A. McFarland. 2011. Influence Flows in the Academy: Using Affiliation Networks to Assess Peer Effects among Researchers. Social Science Research 40: 1001-17. [CrossRef]

Rihoux, Benoît, and Charles. C. Ragin. 2009. Configurational Comparative Methods: Qualitative Comparative Analysis (QCA) and Related Techniques. Thousand Oaks: Sage.

Teune, Henry. 1966. Advantages and Problems of International Collaboration in Social Science Research. Background 10: 177-92. [CrossRef]

Uller, Angela. 1993. Scientific Co-Operation between Europe and Latin America. European Journal of Education $28: 61$. [CrossRef]

Van Rijnsoever, Frank J., and Laurens K. Hessels. 2011. Factors Associated with Disciplinary and Interdisciplinary Research Collaboration. Research Policy 40: 463-72. [CrossRef] 
Wolfe, Alan. 1990. Books vs. Articles: Two ways of Publishing Sociology. Sociological Forum 5: 477-89. [CrossRef] Yamagishi, Toshio, and Karen S. Cook. 1993. Generalized Exchange and Social Dilemmas. Social Psychology Quarterly 56: 235-48. [CrossRef]

Zuckerman, Harriet. 1977. Scientific Elite: Nobel Laureates in the United States. New York: The Free Press.

(c) 2017 by the authors. Licensee MDPI, Basel, Switzerland. This article is an open access article distributed under the terms and conditions of the Creative Commons Attribution (CC BY) license (http:/ / creativecommons.org/licenses/by/4.0/). 